\title{
Hand Function Test
}

National Cancer Institute

\section{Source}

National Cancer Institute. Hand Function Test. NCI Thesaurus. Code C162613.

Various tasks that test an individual's grip strength, pinch strength, and ability to use and feel with their hands. 